\title{
THE EFFECTS OF PSYCHOLOGICAL GAMES ON NONVERBAL COMMUNICATION SKILLS OF THE YOUTH
}

\author{
Koshi Makino \\ Department of Business Administration, Setsunan University (Japan)
}

\begin{abstract}
This study examined the effects of psychological games on nonverbal communication skills. Werewolf-Game was used as a psychological game. Werewolf game has about 10 participants and they were divided into two teams, werewolf team and citizen team. Werewolf tells a lie and attacks the citizens, citizens try to find the wolf by conversation and expel it. As for this game, members of werewolf team have to tell lies and others must find out them, so nonverbal communication skills also become very important.

Participants were 60 university students (36 males and 24 females, Average age is 20.62.). Half participants were divided into an experimental group, and the others were into the control group. The experimental group members played werewolf-games 6 times, and control group members did not. Their nonverbal communication skills ( 3 factors) were measured: nonverbal expression, nonverbal sensitivity, and nonverbal control. The questionnaire was carried out 3 times: 2 weeks before the games, 2 weeks after the games, and 4 weeks after.

According to ANOVA $(2 \times 3)$, interaction effect was significant. There was no significant difference in the means of all scales between experimental and control group before the games. Two weeks after the games, nonverbal expression and nonverbal control skills in experimental group became higher than before, and those two skills were higher than those of control group. In addition, those two skills were maintained high four weeks later. These results indicate the possibility that nonverbal communication skills are promoted by the training which used psychological games.
\end{abstract}

Keywords: Psychological games, nonverbal communication skills, communication skill training, Werewolf-Game.

\section{Introduction}

Communication skills are a part of social skills, which work more directly for interpersonal relationship. Makino (2010) have researched on communication skills of junior-school students and communication skills training for them in Japan. Makino (2012) examined the association between communication skills and friendship, their mental health. According to Makino (2012), as the person who had high communication skills for the same-sex, the friend relations were good and the mental health state was good. Communication skills are indispensable for daily life. On the other hand, we often use nonverbal communication in everyday life. According to Wada (1991), the nonverbal communication skills are classified in three: nonverbal expression, nonverbal sensitivity, and nonverbal control skill. This study aims at the improvement of the nonverbal communication skills using a psychological game as one of the communication skill trainings. That is because that psychological game needs the skill to read feelings from the expression of the others, or the skill to control one's expressions not to show one's real feelings. This study aims at the improvement of the nonverbal communication skills using a psychological game as one of the communication skill trainings.

\section{Objectives}

The purpose of this study was to examine the effects of psychological games on nonverbal communication skills of the youth. This study used Werewolf-Game as a psychological game. Werewolf game has about 10 participants and they were divided into 2 teams, werewolf team and citizen team. Werewolf tells a lie and attacks the citizens, citizens try to find the wolf by conversation and expel it. In this game, werewolf team members lie and try to deceive citizen members and citizen members have to find out their lies, so nonverbal communication of the participants is very important to win. This game was very popular even in Japan in 2013. This study examined the effects of psychological games on nonverbal communication skills. And if the games work to improve their nonverbal communication skills, this study tried to find which skill was trained by the games. This research will make a substantial contribution to communication studies if it becomes clear that some psychological games are useful for nonverbal communication skill trainings. 


\section{Methods}

\subsection{Participants}

Participants were 60 university students (who have experienced few werewolf-games before, 36 males and 24 females, Average age is 20.62.). Half participants were divided into an experimental group, and the others were into the control group. The experimental group members played werewolf-games 6 times, and control group members did not.

\subsection{Procedure}

First of all, participants completed a questionnaire before this research in the classrooms. The questionnaire was presented as a study about daily life among university students. They were told to answer the questions without discussing them with others. After the first investigation, they were divided into 2 groups. Half participants were divided into an experimental group, and the others were the control group. The experimental group members played werewolf-games 6 times for two weeks. On the other hand, control group members did not. Two weeks after the game, the participants of both groups answered the questionnaire again ( 2 weeks after the games). Furthermore, the participants of both groups answered the questionnaire once again (4 weeks after the games).

\subsection{Measures}

The questionnaire was made up of seven scales (and six scales were not analyzed in this study) plus demographic items. It took about 20 minutes to complete.

Nonverbal Communication skills scale. The nonverbal communication skills self-report scale was arranged from Wada (1991). It included 12 items that were rated on a seven-point scale (1=extremely poor, 7= extremely good). Examples of those items were "I can hold down my feelings to reflect on my face." and "I can read the feelings of the others from their expressions." and so on.

According to Wada (1991), the nonverbal communication skills scale was consisted of three factors: nonverbal expression, nonverbal sensitivity, and nonverbal control skill. This study uses these 3 factors as the nonverbal communication skills.

\section{Results}

\subsection{The comparison between experimental group and control group before the games}

The analysis design of this study is ANOVA (2(between: experimental, control) $\times 3$ (within: before, 2 weeks after the games, 4 weeks after the games). The dependent variables are 3 nonverbal communication skill factors.

Table 1 shows means of each skill before the games. As a result of ANOVA of the mean of each factor score between experimental group and control group before the psychological games, there was no significant difference between them. This result revealed that there was no difference in their nonverbal communication skills between experimental and control group before the games.

Table 1. Mean scores of each factor before, 2 weeks, and 4 weeks after the games in two groups

\begin{tabular}{l|ccc|ccc}
\hline $\begin{array}{l}\text { Non-verbal } \\
\text { Communication } \\
\text { Factors }\end{array}$ & \multicolumn{3}{|c|}{ Control group } & \multicolumn{3}{c}{ Experimental group } \\
\hline & Before & $\begin{array}{c}\text { 2 weeks } \\
\text { later }\end{array}$ & $\begin{array}{c}4 \text { weeks } \\
\text { later }\end{array}$ & Before & $\begin{array}{c}\text { 2 weeks } \\
\text { later }\end{array}$ & $\begin{array}{c}\text { 4 weeks } \\
\text { later }\end{array}$ \\
1. Nonverbal expression & 4.47 & 4.53 & 4.57 & 4.51 & 4.92 & 4.76 \\
& $(0.98)$ & $(1.01)$ & $(0.92)$ & $(0.85)$ & $(0.97)$ & $(1.17)$ \\
2. Nonverbal sensitivity & 4.88 & 4.78 & 4.90 & 4.85 & 5.02 & 4.93 \\
& $(1.00)$ & $(0.88)$ & $(1.07)$ & $(0.84)$ & $(0.96)$ & $(1.13)$ \\
3. Nonverbal control & 3.95 & 3.98 & 4.21 & 4.25 & 4.75 & 4.61 \\
& $(1.29)$ & $(1.14)$ & $(1.03)$ & $(1.06)$ & $(1.09)$ & $(1.07)$ \\
\hline
\end{tabular}

\subsection{The comparison between experimental group and control group after the games}

Table 1 shows means of each skill 2 weeks after and 4 weeks after the games. As a result of ANOVA (2(between: experimental, control) $\times 3$ (within: before, 2 weeks after the games, 4 weeks after the games) of the mean of each factor score, there were significant differences in two factors: nonverbal expression skill and nonverbal control skill (see Figure 1 \& Figure 2). 2 weeks after the games, nonverbal expression and nonverbal control skills in experimental group became higher than before, and those two skills were higher than those of control group. In addition, those two skills were maintained high 4 weeks 
later, but they were not higher than those of before the games. There was no significant difference in nonverbal sensitivity skill. These results showed that the participants of experimental group learned how to show their feelings on their faces and how to control their feelings against their true feelings depending on the scene through the games compared with the participants of control group. And those high two skills were maintained four weeks later, which means this effect is not temporary. However, nonverbal sensitivity is considered very important for the were-wolf game, it was not raised up by the games.

Figure 1. Nonverbal expression skill before and after the games.

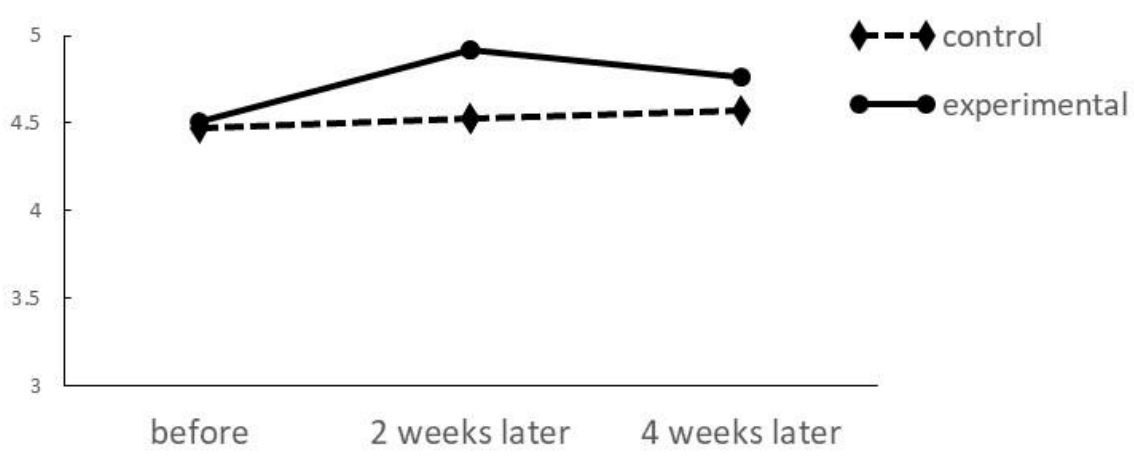

Figure 2. Nonverbal control skill before and after the games.

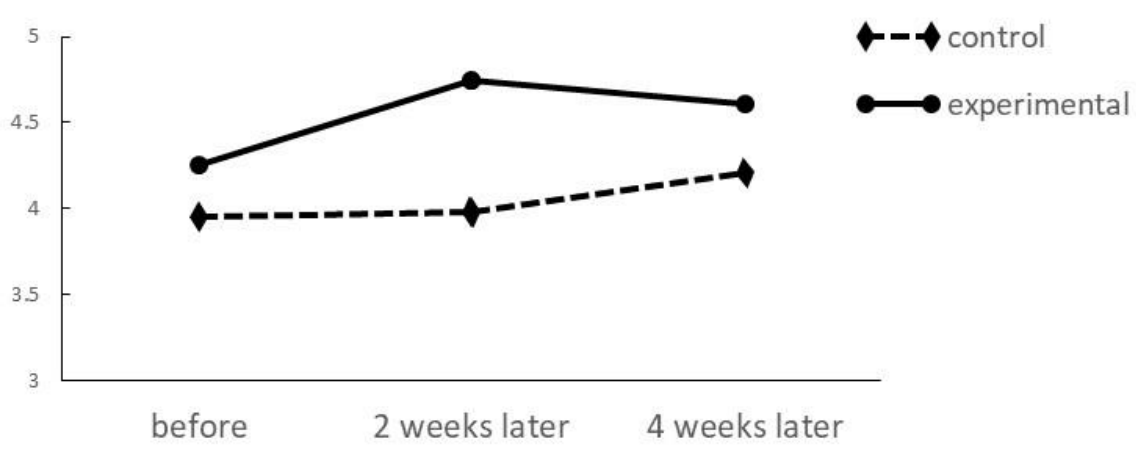

\section{Conclusions}

This study examined the effects of psychological games on nonverbal communication skills of the youth. The psychological games in this experiment raised two nonverbal communication skills of the participants in the experimental group and those two skills were higher than those of control group, but the psychological mechanism was not elucidated. The participants acquired skills how to show their feelings on their faces and how to control their feelings against their true feelings depending on the scene while enjoying the games. And those two skills were maintained high four weeks later. These results indicate the possibility that parts of nonverbal communication skills are promoted by the training using the psychological games.

\section{References}

Makino, K. (2010). A Development of the Communication Skills Training for Junior High School Students (3). - The Effects of Communication Skills Training on Junior High School Students in Japan. - Journal of Business Administration and Information, 18, 1-9.

Makino, K. (2012). The Communication Skills and Friendship in Adolescence - The Sex and Grade Differences of Communication Skills for Friends of the Same and Opposite Sex - Journal of Business Administration and Information, 20, 17-32.

WADA, M. (1991). A study of interpersonal competence: Construction of nonverbal skill scale and social skill scale The Japanese Journal of Experimental Social Psychology. 31, 49-59. 